\title{
Fluorescence polarization assay to detect the presence of traces of ciprofloxacin
}

\begin{abstract}
Hiyam El Kojok ${ }^{1}$, Nada El Darra ${ }^{2}$, Mahmoud Khalii ${ }^{1}$, Alessandro Capo ${ }^{3}$, Angela Pennacchio ${ }^{3}$, Maria Staiano ${ }^{3}$, Alessandra Camarca ${ }^{3}$, Sabato D'Auria ${ }^{3 *}$ \& Antonio Varriale ${ }^{3}$

Detection of ciprofloxacin residues in milk by sensitive and rapid methods is of great interest due to its use in the treatment of dairy livestock health. Current analytical approaches to antibiotics detection, are laboratory-based methods and they are time-consuming and require trained personnel. To cope this problem, we propose an assay, based on fluorescence polarization principle, able to detect the presence of ciprofloxacin in diluted milk sample without any pre-treatment. The proposed method is based on the use of ciprofloxacin-protein conjugate labeled with near infrared fluorescence dye, which upon binding to specific antibody causes an increase of the fluorescence polarization emission signal. The developed assay allows for the detection of ciprofloxacin at a concentration of $1 \mathrm{ppb}$, which represents an amount lower than the maximum residual limit (MRL) of ciprofloxacin in milk, as set by the European Union regulation (100 ppb).
\end{abstract}

The antibiotics treatment plays a crucial role in dairy livestock health ${ }^{1}$. It is being used for therapeutic purposes as well as for improving breeding efficiency. However, this treatment can leave residues of antibiotics in foods of animal origin (milk and meat), and consequently an increase of the human exposure to antibiotics ${ }^{2}$. While assessing the usage of antibiotic residues, the exceptional use of such drugs was legally considered ${ }^{3}$. Hence, the risk of the presence of antibiotic residues in milk and dairy products could increase in case that a required elimination period of them in food is not properly defined.

Antibiotic residues in milk and dairy products present detrimental consequences on the consumer health, causing disturbances in the intestinal flora as well as allergic reactions that could lead to anaphylaxis ${ }^{4}$. Moreover, antibiotic residues might increase microbial resistance, a major health risk ${ }^{5}$. Among anti-bacterial agents used for the management of infections in dairy livestock, ciprofloxacin, belonging to the fluoroquinolone class, is the common antibiotic used in case of pulmonary, urinary and digestive infections ${ }^{6}$. However, ciprofloxacin could cause hypersensitivity in humans ${ }^{7}$. Due to the importance of considering the presence of ciprofloxacin in milk, a residue surveillance of anti-microbial presence is crucial to support food-farming practices, upraising consequently the food safety level. It is to be noted that the maximum residual limit (MRL) for ciprofloxacin in milk has been fixed at $100 \mathrm{ppb}$ (Council Regulation EEC/2377/90). In Lebanon, few studies have investigated the presence of antibiotic residues in milk ${ }^{8-10}$. A recent study showed that ciprofloxacin and oxytetracycline are mostly found antibiotics in milk in Lebanon (personal communication).

Currently, laboratory-based methods, such as liquid chromatography-mass spectrometry (LC-MS), high performance liquid chromatography (HPLC) $)^{11-13}$ and microbiological assays ${ }^{14}$ are the common used approaches for ciprofloxacin detection. These methods have different restrictions that make them challenging to apply outside the laboratory. Therefore, there is a growing need for quick, easy, and not expensive methods to detect and manage ciprofloxacin residues in food matrices ${ }^{15-18}$.

Fluorescence polarization assays represent a valid alternative to detect chemical contaminants in food and milk samples ${ }^{19}$. In this work, a fluorescence polarization assay for the detection of the presence of ciprofloxacin in milk was developed using ad hoc synthesized fluorescence ciprofloxacin-conjugate (GlnBP-CPFX), covalently labeled with a near-infrared (NIR) fluorescence dye, and commercial monoclonal anti-ciprofloxacin antibody. The principle of the assay is that, at stable temperature and viscosity, the fluorescence polarization emission value is related on the molecular size of the excited molecule ${ }^{20}$. Thus, a competitive immunoassay has been deployed

${ }^{1}$ Department of Biological Sciences, Faculty of Science, Beirut Arab University, Beirut, Lebanon. ${ }^{2}$ Beirut Arab University, Faculty of Heath Sciences, Tarik El Jedidah, Beirut, P.O.Box: 115020 Riad EL Solh 1107 2809, Beirut, Lebanon. ${ }^{3}$ Institute of Food Science, CNR, Via Roma, 64, 83100, Avellino, Italy. *email: sabato.dauria@cnr.it 

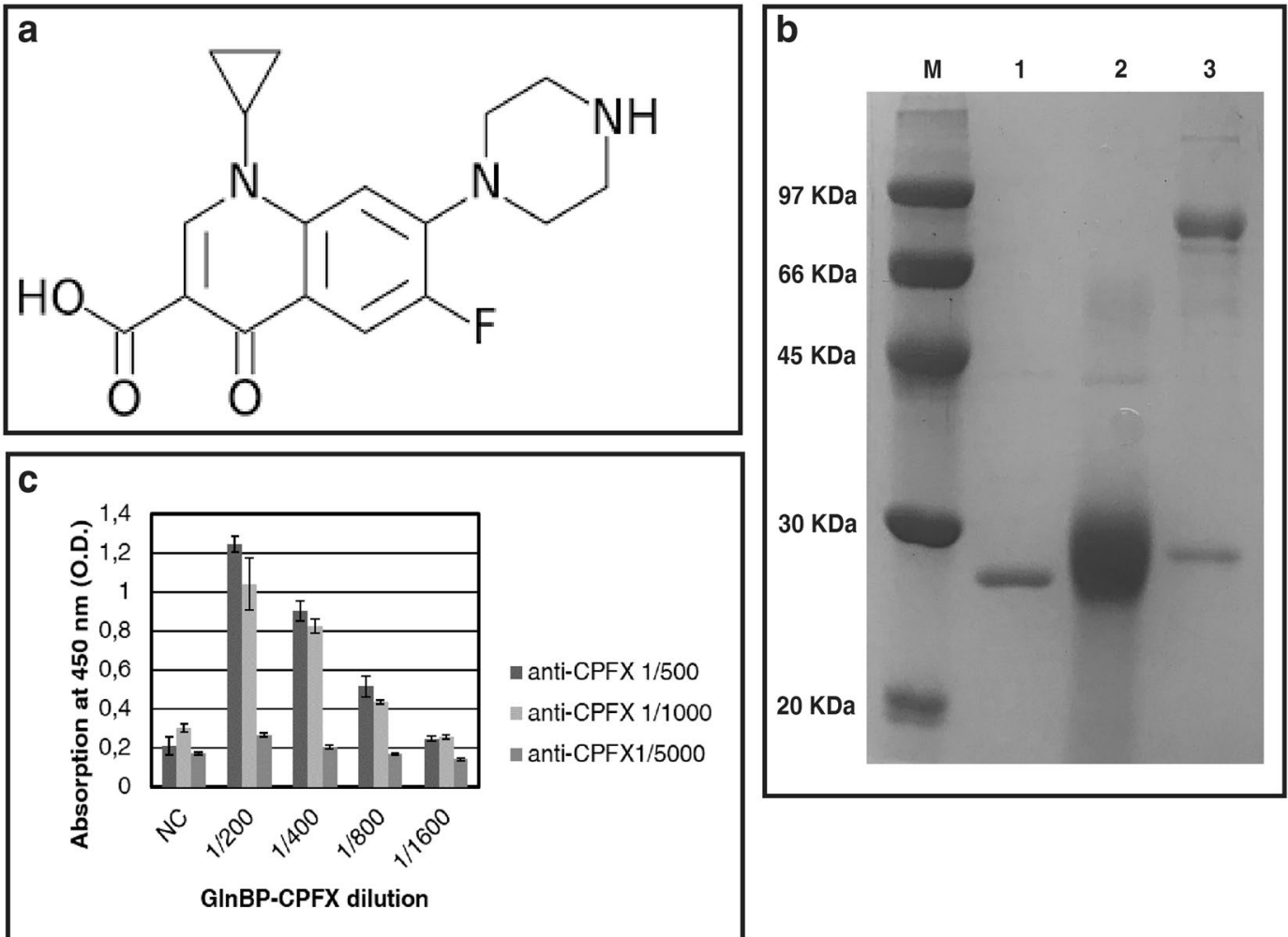

Figure 1. Chemical structure of ciprofloxacin (a) SDS-PAGE of the GlnBP, GlnBP-CPFX conjugate and monoclonal anti-CPFX (b) anti-CPFX titer (c).

to directly detect ciprofloxacin residues in commercial diluted milk solution sample. The obtained results show a high sensibility of the assay (1.0 ppb) respect the maximum residual limit (MRL) set by the European Union regulation (100 ppb). Finally, it is worth to note that this method can be transferred into a hand-held device capable to acquire fluorescence polarization changes when ciprofloxacin derivative and anti-ciprofloxacin antibodies interacts.

\section{Methods}

Reagents. All purchased materials were the highest quality available. Ciprofloxacin CPFX, 1-[3-(Dimethylamino)-propyl]-3-ethylcarbodiimide (EDC) and Sodium phosphate were purchased from SigmaAldrich (St. Louis, MO, USA), Potassium dihydrogen phosphate was purchased from Applicam, Germany. Mouse monoclonal anti-ciprofloxacin antibody was purchased from Abbexa (Cambridge, UK). Goat polyclonal antimouse IgG-HRP conjugate (secondary antibody) was purchased from Abcam (Cambridge, UK). ECL detection reagents and Immobilon-PSQ PVDF Membrane were purchased from Amersham Biosciences (GE Healthcare Switzerland) and from Merck, USA respectively. The Enzyme substrate 3,5-tetramethylbenzidine (TMB) was purchased from Sigma Aldrich while the Microplates (96-well), Nunc LockWell C8 MaxiSorp was purchased from Thermo Scientific. The fluorescent Amine-Reactive Dye CF647, Succinimidyl-ester was obtained from Biotium (Freemont, USA).

GInBP-CPFX conjugate preparation. The GlnBP-CPFX molecules was prepared by conjugation the $\mathrm{CPFX}$ to a recombinant glutamine-binding protein $(\mathrm{GlnBP})$ isolated from Escherichia coli ${ }^{21}$. Briefly, the conjugate was synthesized through carbodiimide method described by ${ }^{15}$ with slight modifications. Ciprofloxacin $1.0 \mathrm{ml}$ $(26.2 \mathrm{mg} / \mathrm{ml})$, was mixed with $1.0 \mathrm{ml}$ of $\mathrm{GlnBP}(4.5 \mathrm{mg} / \mathrm{ml})$ and EDC $(314 \mathrm{mg} / \mathrm{ml}$ in $0.01 \mathrm{M}$ Phosphate buffer, $\mathrm{pH}$ 5.0). The obtained mix reaction was allowed to occur at $28^{\circ} \mathrm{C}$ for $2 \mathrm{~h}$. Dialysis of the reaction mixture was carried out for two days in $0.01 \mathrm{M}$ phosphate buffer, $\mathrm{pH} 5.0$, and the dialyzing buffer was changed twice per day.

Western blotting. Western blotting experiment was performed according to Varriale ${ }^{19}$. In brief, GlnBP, CPFX-GlnBP and CPFX antibodies ( $4 \mu \mathrm{g}$ each) were separated by $12 \%$ SDS-PAGE and then transferred overnight at $4{ }^{\circ} \mathrm{C}$ onto a Polyvinylidene difluoride (PVDF) membrane. After this step, membrane was blocked using TBS containing $5 \%$ of milk for $30 \mathrm{~min}$ at room temperature, then washed with TBST (three washes for 10 minutes each time.) and incubated with purified mouse monoclonal CPFX antibodies (1:1000) for $1 \mathrm{hr}$. at $37^{\circ} \mathrm{C}$. After this incubation step, the membrane was washed (three times) and then incubated with goat anti-mouse IgG-HRP conjugate $(1: 5000)$ for $1 \mathrm{~h}$ at $37^{\circ} \mathrm{C}$. Finally the protein bands developed using ECL. 


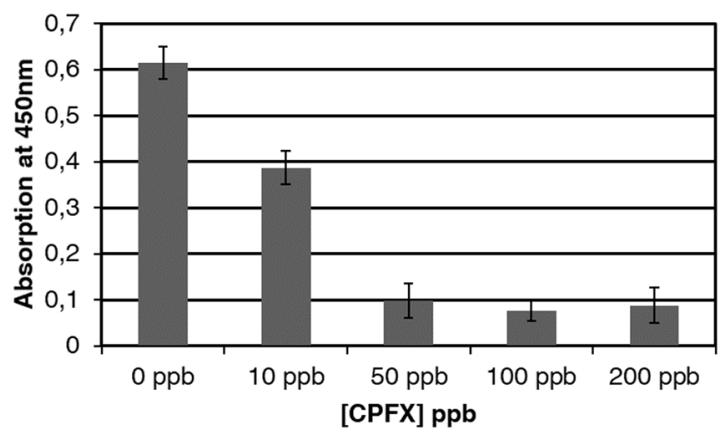

Figure 2. Competitive indirect ELISA test. The plate was coted with $0.00625 \mathrm{mg} / \mathrm{ml} \mathrm{GlnBP-CPFX}$ and the antiCPFX was diluted 1:1000. All the measurements were done in triplicate.

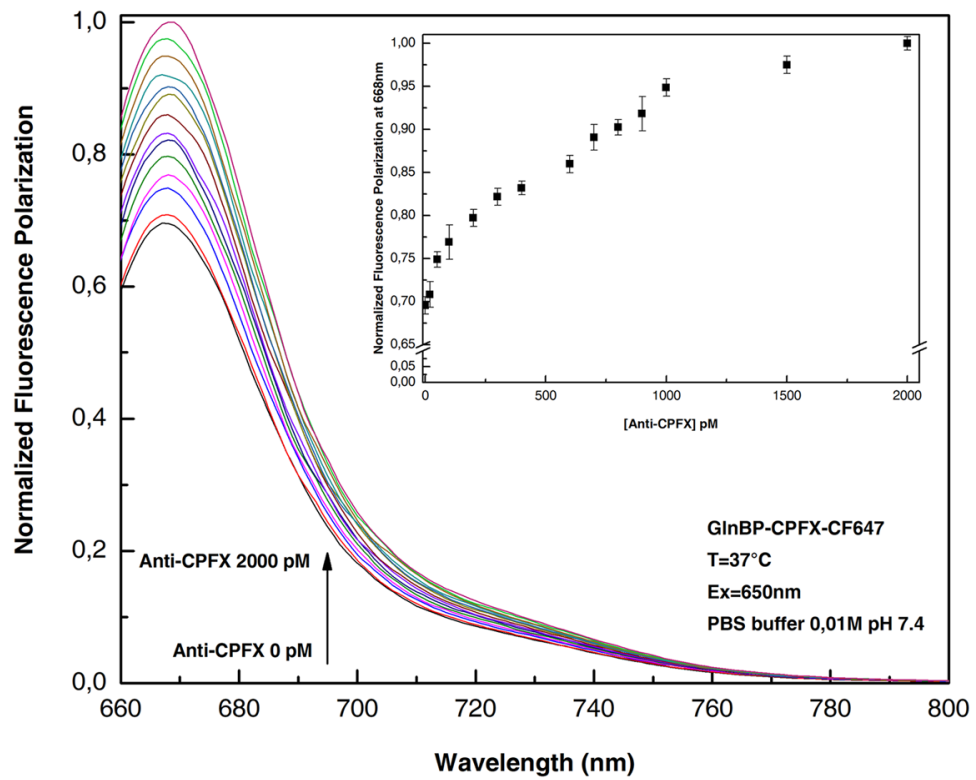

Figure 3. Fluorescence polarization emission spectra of ciprofloxacin-GlnBP-CF647 in the absence and presence of an increasing concentration of anti-ciprofloxacin. Variation of the maximum fluorescence value at $668 \mathrm{~nm}$ as a function of the antibody concentration (inset). All the measurements were done in PBS buffer 0.01 $\mathrm{M} \mathrm{pH} 7.4$ at $37^{\circ} \mathrm{C}$.

Antibody titer determination. To determine the antibody titer according to de Champdoré ${ }^{19}$ an ELISA test was performed as described by Varriale ${ }^{18}$ with slight modifications. Each well of a 96-well plate was coated by CPFX-GlnBP antigen $(0.00625 \mathrm{mg} / \mathrm{ml})$ in bicarbonate buffer $(0.05 \mathrm{~mol} / \mathrm{L}, \mathrm{pH} 9.6)$, with different dilutions $(1 / 200$, $1 / 400,1 / 800$ and $1 / 1600)$ at $4{ }^{\circ} \mathrm{C}$ overnight. As control, some wells were coated by coating buffer and other wells were coated by GlnBP protein. The wells were washed three times with washing buffer (PBS $0.01 \mathrm{~mol} / \mathrm{L} \mathrm{pH} 7.4$ containing $0.05 \%$ Tween-20; PBST) and after the incubation with $200 \mu \mathrm{l} /$ well of blocking buffer $(0.02 \mathrm{~mol} / \mathrm{L} \mathrm{PBS}$ at $\mathrm{pH} 7.4$ including $2 \%(\mathrm{w} / \mathrm{w})$ glycine), at $37^{\circ} \mathrm{C}$ for $2 \mathrm{~h}$, the plate was rinsed three times. After this step, $100 \mu \mathrm{l}$ of monoclonal antibodies of different dilutions were incubated in the coated wells at $37^{\circ} \mathrm{C}$ for $1 \mathrm{~h}$. The plate was rinsed (three times), goat anti-mouse IgG-HRP antibody $(1: 5000,100 \mu \mathrm{l} /$ well) was added, and the wells were incubated for $1 \mathrm{~h}$ at $37^{\circ} \mathrm{C}$. Finally, the enzyme substrate solution (TMB) was added $(50 \mu \mathrm{l} /$ well), and the wells were incubated at $37^{\circ} \mathrm{C}$, then color development was quenched by adding stopping solution $\mathrm{H}_{2} \mathrm{SO}_{4}(2 \mathrm{~mol} / \mathrm{L}, 50 \mu \mathrm{l}$ /well) after $10 \mathrm{~min}$. A micro-plate reader was used to measure the absorbance at $450 \mathrm{~nm}$.

Fluorescence labelling of CPFX-GInBP. The conjugate CPFX-GlnBP was labeled according to Varriale ${ }^{18}$. $100 \mu \mathrm{l}$ of CPFX-GlnBP $(5 \mathrm{mg} / \mathrm{ml})$ in $1 \mathrm{~mol} / \mathrm{L}$ sodium bicarbonate at $\mathrm{pH} 8.3$ was mixed with the dye CF647 (molar ratio 1:12) and the reaction mixture was kept at room temperature for 1 hour. Separation of CPFX-GlnBP-CF647 from un-reacted probe was done by gel filtration (G25 Sepharose) and extensive dialysis against PBS 0.01 mol/L $\mathrm{pH} 7.4$. 


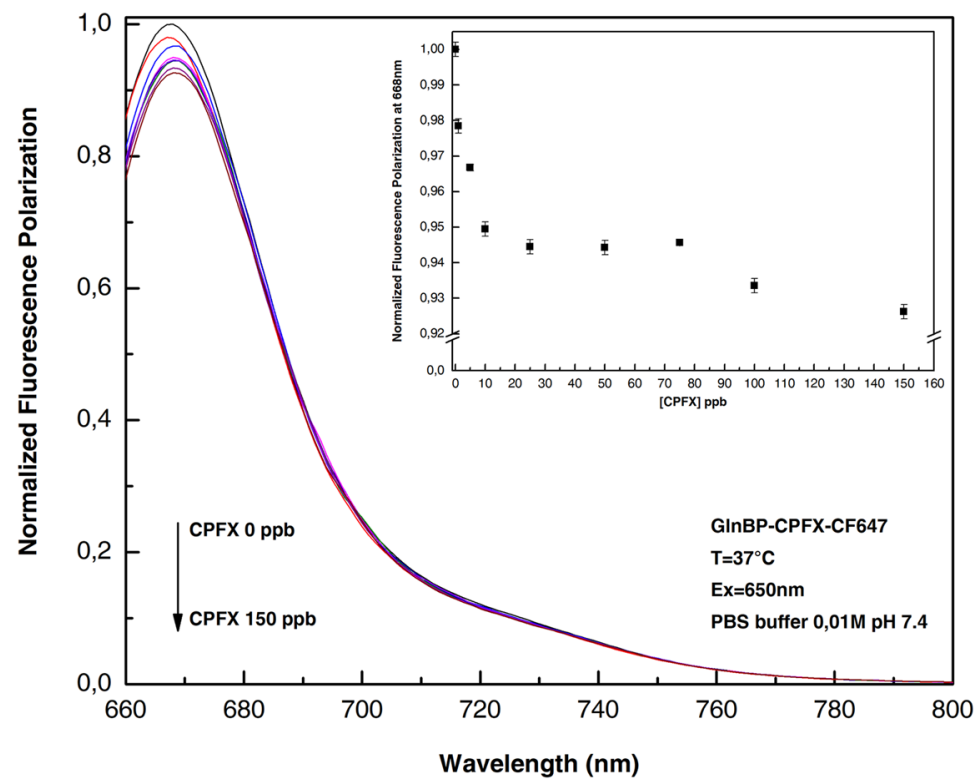

Figure 4. Fluorescence polarization emission spectra of ciprofloxacin-GlnBP-CF647 with increasing concentration of unlabeled Ciprofloxacin in the presence of $1000 \mathrm{pM}$ anti-ciprofloxacin antibody. All the measurements were done in PBS buffer $0.01 \mathrm{M} \mathrm{pH} 7.4$ at $37^{\circ} \mathrm{C}$.

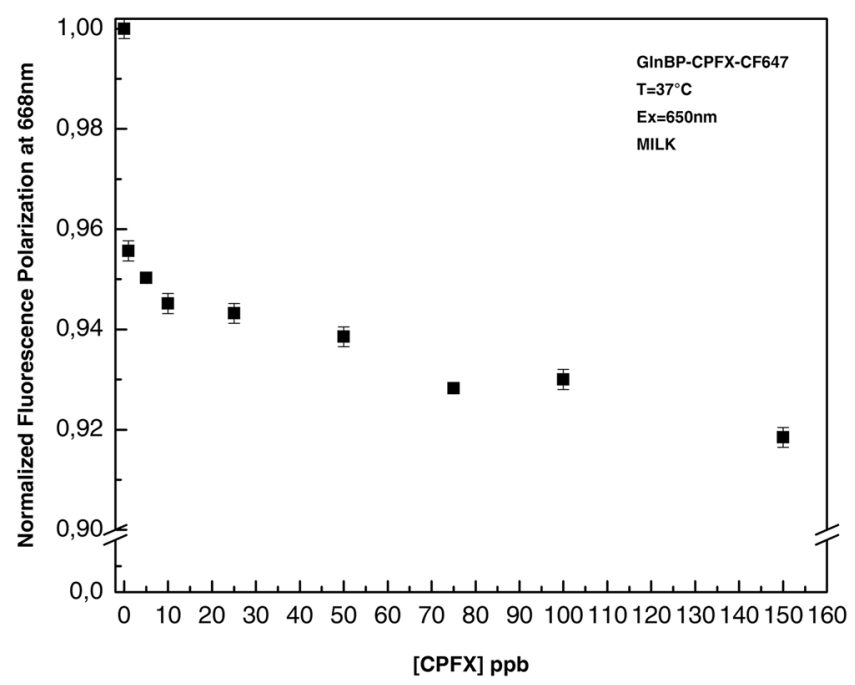

Figure 5. Dose-response curve of CPXF detection. Titration of fluorescence polarization immune assay with increasing concentrations of un-labeled CPXF. All the measurements were performed in milk diluted 100 times in PBS buffer $0.01 \mathrm{MpH} 7.4$ at $37^{\circ} \mathrm{C}$.

Steady-state fluorescence measurements. Steady-state measurements were performed using a fluorescence spectrometer FP-8600 (Jasco-Japan). The polarization emission spectra of CPFX-GlnBP-CF64 were acquired setting excitation value at $650 \mathrm{~nm}$ and recording between $654 \mathrm{~nm}$ and $800 \mathrm{~nm}$. In antibody binding experiments, the fluorescence spectra were carried out through incubation, overnight at $37^{\circ} \mathrm{C}$, of CPFX-GlnBP-CF647 with increasing concentrations of anti-CPFX. The antibody concentration tested was from $20 \mathrm{pM}$ to $2000 \mathrm{pM}$ in $0.01 \mathrm{~mol} / \mathrm{L}$ PBS buffer at $\mathrm{pH}$ 7.4. The polarization fluorescence measurements were obtained with polarized filter, in excitation and emission, set at vertical position.

Ciprofloxacin competitive immunoassay. A competitive polarization immunoassay with fixed concentration of antibody $(1000 \mathrm{pM})$ and increasing concentration of un-labeled ciprofloxacin from $1 \mathrm{ppb}$ to $150 \mathrm{ppb}$ was performed. The fluorescence polarization measurements were performed in both PBS buffer $(0.01 \mathrm{~mol} / \mathrm{L}, \mathrm{pH} 7.4)$ and milk diluted 100 times in PBS. The measurements were performed at the end of an overnight incubation at $37^{\circ} \mathrm{C}$ with the unlabeled ciprofloxacin, and the excitation and emission polarized filters were set at vertical position. 


\section{Results}

In this study, we describe a fluorescence polarization assay for the detection of the ciprofloxacin. Ciprofloxacin is a fluoroquinolones (FQ) used in the management of pulmonary, urinary and digestive infections in animal livestock. As all antibiotic molecules, ciprofloxacin is a very small molecule (Fig. 1a) unable to elicit an immunological response in an organism. For the assay development, we selected specific commercial monoclonal antibody against the CPFX. In order to characterize the antibody binding features and avoid any cross-reactivity effects, we conjugated the CPFX to a protein carrier. For this purpose, according to Varriale ${ }^{18}$, the CPFX was conjugate to the recombinant GlnBP isolated from $E$. coli by the well-known conjugation processes using EDC $^{22,23}$. At the end of the conjugation process, SDS-PAGE analysis of the GlnBP and GlnBP-CPFX conjugate was performed to verify the purity of the sample preparations and to evaluate the conjugation effect on the molecular weight of GlnBP (Fig. 1b). The obtained conjugate molecule GlnBP-CPFX, was labeled with a specific fluorescence probe (CF647) and the achieved fluorescence molecule (GlnBP-CPFX-CF647) was used for the development of the competitive fluorescence polarization immunoassay.

Western blotting and ELISA results. To confirm the specificity of monoclonal antibodies versus the produced GlnBP-CPFX conjugate, western blotting and indirect ELISA tests were performed. In the western blotting experiments, the response was observed against GlnBP-CPFX, while a negative response was showed for GlnBP and BSA (data not shown). On the contrary, an ELISA test was done to evaluate the antibody titer. The value was calculate according to Di Giovanni ${ }^{24}$ and as presented in Fig. 1c, it was possible to perform the ELISA test with monoclonal anti-CPFX up to 1 to 1000 dilution.

Competitive ELISA test. A competitive indirect ELISA was performed to set up a sensitive assay for CPFX detection. The plate was coated with fixed amount of $\operatorname{GlnBP}-\operatorname{CPFX}(6,25 \mu \mathrm{g} / \mu \mathrm{l})$ and incubated with anti-CPFX in presence of increased concentration of un-labeled CPFX. In Fig. 2 is reported the variation of the absorption at $450 \mathrm{~nm}$ as consequence of the increased concentration of the CPFX. The obtained data show a significant variation of the signal (about 1,5 times) a very low concentration of CPFX (10 ppb).

Fluorescence polarization assay. In Fig. 3 are depicted the polarized emission spectra of GlnBP-CPXF-CF647 acquired at $37^{\circ} \mathrm{C}$. The sample was excited at $650 \mathrm{~nm}$ and shows a maximum of emission centered at $668 \mathrm{~nm}$. The anti-CPFX was added at concentrations from $20 \mathrm{pM}$ to $2000 \mathrm{pM}$ and the obtained results show an increase of the polarization signal as consequence of the increase amount of antibody in solution. In the inset of Fig. 3, is reported the variation of the maximum of polarized fluorescence emission at $668 \mathrm{~nm}$ versus the antibody concentration. The increase of intensity is registered and correlated to the addition of increased concentrations of antibodies.

Competitive assay. A competitive fluorescence polarization immune-assay was performed to study the competition between the un-labeled CPFX and GlnBP-CPFX-CF647. For this purpose, samples of anti-CPFX antibody $(1000 \mathrm{pM})$ were incubated in the presence of different amounts of un-labeled CPXF. The data reported in Fig. 4, show the reduction of polarized fluorescence emission at the increasing concentration of un-labelled CPFX. This effect, due by the competition between the anti-CPFX to both GlnBP-CPFX-CF647 and unlabeled CPFX present in solution, allows to detect traces of the CPFX in solution. Figure 4 (inset), reports the change of the fluorescence intensity as a function of CPFX concentration. The presence of a very low concentration of CPFX in solution produces a reduction of the fluorescence emission.

Finally, the developed assay was tested in real food matrices. A competitive experiment was performed diluting increased quantities of CPFX in diluted milk samples. Figure 5 shows the variation of the polarization fluorescence intensity as function of CPFX concentration in diluted milk (1:100). The results show that it is possible to detect less than $1.0 \mathrm{ppb}$ of CPFX directly in the milk solution. This value is lower than the value reported in the EU regulation (100 ppb).

\section{Conclusion}

Veterinary drugs residues, such as antibiotics, released in animal origin foodstuff have an important consequence for human health and so their detection has become the main aim of food safety control. In this work, we have described the development of a near-infrared fluorescence polarization assay for the detection of the antibiotic CPFX directly in diluted milk solution. The amount of antibiotics in food is rigorously regulated by the European Union and MRLs has been established. This value for ciprofloxacin in milk is $100 \mathrm{ppb}$ (Council Regulation EEC/2377/90).

Received: 20 September 2019; Accepted: 10 February 2020;

Published online: 12 March 2020

\section{References}

1. Quintanilla, P., Beltrán, M. C., Peris, B., Rodríguez, M. \& Molina, M. P. Antibiotic residues in milk and cheeses after the off-label use of macrolides in dairy goats. Small Rumin. Res. 167, 55-60, https://doi.org/10.1016/j.smallrumres.2018.08.008 (2018).

2. Bergwerff, A. A. \& Schloesser, J. Antibiotics and Drugs Residue Determination. Encyclopaedia of Food Science, Food Technology and Nutrition, 254-261, https://doi.org/10.1016/B0-12-227055-X/00052-3 (2003).

3. European Parliament and the Council of the European Union. Directive 2001/82/EC of the European Parliament and of the Council of 6 November 2001 on the Community Code Relating to Veterinary Medicine. (2001).

4. Graham, F. et al. Risk of allergic reaction and sensitization to antibiotics in foods. Ann. Allergy. Asthma. Immunol. 113, 329-330, https://doi.org/10.1016/j.anai.2014.06.029 (2014). 
5. EFSA. The European Union summary report on antimicrobial resistance in zoonotic and indicator bacteria from humans, animals and food in 2014. EFSA Journal 14, 4380 (2016).

6. Kalunke, R. M., Grasso, G., D’Ovidio, R., Dragone, R. \& Frazzoli, C. Detection of ciprofloxacin residues in cow milk: a novel and rapid optical $\beta$-galactosidase-based screening assay. Microchem. J. 136, 128-132 (2018).

7. Omotoso, A. B. \& Omojola, A. B. Fluoroquinolone residues in raw meat from open markets in Ibadan, Southwest, Nigeria. International Journal of Health, Animal Science and Food Safety 2 (2015).

8. Choueiri, M. G. Emerging contaminants in Lebanon: antibiotic residues in cow manure and soil. American University of Beirut, Department of Land and Water Resources (2008).

9. Zeina, K., Pamela, A. K. \& Fawwak, S. Quantification of antibiotic residues and determination of antimicrobial resistance profiles of microorganisms isolated from bovine milk in Lebanon. Food and Nutrition Sciences 4, 1 (2013).

10. Kabrite, S., Bou-Mitri, C., El Hayek Fares, J., Hassan, H. F. \& Matar Boumosleh, J. Identification and dietary exposure assessment of tetracycline and penicillin residues in fluid milk, yogurt, and labneh: A cross-sectional study in Lebanon. Veterinary World 12, 527-534 (2019).

11. Johnston, L., Mackay, L. \& Croft, M. Determination of quinolones and fluoroquinolones in fish tissue and seafood by highperformance liquid chromatography with electrospray ionisation tandem mass spectrometric detection. J. Chromatogr. A 982, 97-109, https://doi.org/10.1016/S0021-9673(02)01407-3 (2002).

12. van Vyncht, G. et al. Multiresidue determination of (fluoro)quinolone antibiotics in swine kidney using liquid chromatographytandem mass spectrometry. J. Chromatogr. A 952, 121-129, https://doi.org/10.1016/s0021-9673(02)00092-4 (2002).

13. Espinosa-Mansilla, A., de la Pena, A. M., Gomez, D. G. \& Lopez, F. S. Determination of fluoroquinolones in urine and serum by using high performance liquid chromatography and multiemission scan fluorimetric detection. Talanta 68, 1215-1221, https://doi. org/10.1016/j.talanta.2005.07.035 (2006).

14. Kurittu, J., Lonnberg, S., Virta, M. \& Karp, M. A group-specific microbiological test for the detection of tetracycline residues in raw milk. J. Agric. Food Chem. 48, 3372-3377, https://doi.org/10.1021/jf9911794 (2000).

15. Liu, L. et al. Development of an immunochromatographic strip test for rapid detection of ciprofloxacin in milk samples. Sensors (Basel) 14, 16785-16798, https://doi.org/10.3390/s140916785 (2014).

16. Pennacchio, A. et al. A novel fluorescence polarization assay for determination of penicillin G in milk. Food Chem. 190, 381-385, https://doi.org/10.1016/j.foodchem.2015.05.127 (2016).

17. Pennacchio, A., Varriale, A., Esposito, M. G., Staiano, M. \& D’Auria, S. A near-infrared fluorescence assay method to detect patulin in food. Anal. Biochem. 481, 55-59, https://doi.org/10.1016/j.ab.2015.04.027 (2015).

18. Varriale, A. et al. A Fluorescence Polarization Assay To Detect Steroid Hormone Traces in Milk. J. Agric. Food Chem. 63, 9159-9164, https://doi.org/10.1021/acs.jafc.5b03689 (2015).

19. de Champdore, M. et al. A new competitive fluorescence assay for the detection of patulin toxin. Anal. Chem. 79, 751-757, https:// doi.org/10.1021/ac0618526 (2007).

20. Lakowicz, J. R. Principles of Fluorescence Spectroscopy. Springer, New York, (3rd edition) (2006).

21. Staiano, M. et al. Unfolding and Refolding of the Glutamine-Binding Protein from Escherichia coli and Its Complex with Glutamine Induced by Guanidine Hydrochloride. Biochemistry 44, 5625-5633, https://doi.org/10.1021/bi0478300 (2005).

22. Huang, B. et al. Preparation of high-affinity rabbit monoclonal antibodies for ciprofloxacin and development of an indirect competitive ELISA for residues in milk. Journal of Zhejiang University SCIENCE B 11, 812-818, https://doi.org/10.1631/jzus. B1000055 (2010).

23. Varriale, A. et al. A surface plasmon resonance-based biochip to reveal traces of ephedrine. Analytical Methods 4, 1940-1944, https://doi.org/10.1039/C2AY25231G (2012).

24. Di Giovanni, S., Zambrini, V., Varriale, A. \& D’Auria, S. Sweet Sensor for the Detection of Aflatoxin M1 in Whole Milk. ACS Omega 4, 12803-12807, https://doi.org/10.1021/acsomega.9b01300 (2019)

\section{Acknowledgements}

The authors thankfully acknowledge the Lebanese Agriculture Research Institute for its continuous support.

\section{Author contributions}

S.D., N.E.D. and M.K.: Conceived and designed the experiments. H.E.K., A. Capo. A.P.: Performed the experiments. H.E.K., A.V., M.S. and A. Capo: Analyzed the data. M.S. and A. Camarca: Contributed reagents/ materials/analysis tools. H.E.K. and A. Capo: Prepared Figs. 1-5: H.E.K., N.E.D., A.V. and S.D.: Wrote the paper. All authors reviewed and approved the final version of the manuscript.

\section{Competing interests}

The authors declare no competing interests.

\section{Additional information}

Supplementary information is available for this paper at https://doi.org/10.1038/s41598-020-61395-3.

Correspondence and requests for materials should be addressed to S.D.A.

Reprints and permissions information is available at www.nature.com/reprints.

Publisher's note Springer Nature remains neutral with regard to jurisdictional claims in published maps and institutional affiliations.

Open Access This article is licensed under a Creative Commons Attribution 4.0 International License, which permits use, sharing, adaptation, distribution and reproduction in any medium or format, as long as you give appropriate credit to the original author(s) and the source, provide a link to the Creative Commons license, and indicate if changes were made. The images or other third party material in this article are included in the article's Creative Commons license, unless indicated otherwise in a credit line to the material. If material is not included in the article's Creative Commons license and your intended use is not permitted by statutory regulation or exceeds the permitted use, you will need to obtain permission directly from the copyright holder. To view a copy of this license, visit http://creativecommons.org/licenses/by/4.0/.

(C) The Author(s) 2020 